\title{
Never the Twain Shall Meet? How Narrativism and Experience can be Reconciled by Dialogical Ethics.
}

\author{
Anton Froeyman, \\ Centre for Logic and Philosophy of Science, Ghent University \\ Blandijnberg 2, 9000 Gent, Belgium \\ Anton.froeyman@ugent.be
}

Anton froeyman@yahoo.com

\begin{abstract}
In this paper, I question the unspoken assumption in historical theory that there is a tradeoff between language or narrative on the hand and experience or presence on the other. Both critics and proponents of historical experience seem to presuppose that this is indeed the case. In this paper, I argue that this is not necessarily true, and I analyse how the opposition between language and experience in historical theory can be overcome. More specifically, I identify the necessary conditions for a philosophy of language that can be the basis for this. Secondly, I will also suggest and present one specific instance of such a solution. I argue that the existential philosophies of language of Martin Buber and Emmanuel Levinas can be exactly the kind of theory we need. For Buber and Levinas, language is not a means of accessing reality, but rather a medium of encounters between human beings. I present Levinas' and Buber's arguments, discuss how their views could be applied to the writing of history and what the resulting picture of the writing of history could look like.
\end{abstract}

Keywords: language, narrativism, experience, Buber, Levinas 


\section{Introduction}

In the twenty-five years after 1970 so much was achieved by theorists in revising the epistemological basis of historical work that they understandably lost sight of its object. The past-in-itself became an absence, a nothingness, a page on which to write, a place for dreams and images. A constructed factuality announced itself as the past's sole presence, representation is only strangulated voice, colligation its distant tyrant. ${ }^{1}$

For the last decade or so, recognition has been spreading that the linguistic turn that had motivated much advanced work in the humanities is over. The massive tide of language that connected analytic philosophy with pragmatism, anthropology with social history, philosophy of science with deconstruction, has receded; we are now able to look across the sand to see what might be worth salvaging before the next waves of theory and research begin to pound the shore. ${ }^{2}$

These quotes from papers by Michael Roth and Michael Bentley are of course far from a neutral description of the state of the field of theory of history. They are two miniature pieces of substantial philosophy of history about the discipline of theory of history itself, and (as substantial philosophy of history is prone to do) they disguise a particular programmatic agenda as a claim about the course of history itself. Nevertheless, Bentley and Roth's comments are a sign of the times. After almost forty years of research from a narrativistic point of view, the time has come to evaluate this tradition. This does not necessarily mean that the narrativistic turn in theory of history is passé. Some might even argue that the real linguistic and narrativistic turn, a true and radical application of the insights of post-structuralist philosophy and/or Whitean narrativism, has not even yet begun. ${ }^{3}$ Plausibly, the majority of theorists of history will probably still be appreciative of the accomplishments of narrativism, but might also want to take its insights into new and uncharted territories. In any case, there is little doubt that narrativism is still an important approach or 'school' within theory of history. Nevertheless, narrativism is no longer alone, and perhaps not even dominant anymore. Recently, several new approaches within theory of history have come to the fore, and if we want to address the question of the legacy and the future of narrativism, one of the most central questions is how narrativism will relate to these new kids on the block.

Perhaps the most prominent alternative for the central position of narrativism within theory of history is the group of theories clustering around the notions of 'historical experience' and 'presence'. In the last fifteen years, there has been a boom in the number of publications on historical experience and experience-related notions ${ }^{4}$. Theorists such as Frank Ankersmit, Eelco Runia and Hans-Ulrich Gumbrecht have developed these concepts in order to describe and advocate a more personal, direct, authentic and intuitive, and less intellectualized and scholarly relation with the past. ${ }^{5}$ However, the rise of historical experience and 'presence' as has also been met with concern and controversy, particularly from scholars strongly inspired by narrativism, postmodernism and the linguistic turn. Much of this criticism has to do with the way presence and historical experience deal with language. Narrativists and other theorists of history sympathetic to the linguistic turn are afraid

\footnotetext{
${ }^{1}$ Michael Bentley, Past and Presence: Revisiting Historical Ontology, History and Theory 45/3 (2006), 349.

${ }^{2}$ Michael Roth, Ebb Tide, History and Theory 46/1 (2007), 66.

${ }^{3}$ Kalle Pihlainen, The End of Oppositional History?, Rethinking History 15/4 (2011).

${ }^{4}$ The bibliography of the International Network for Theory of History lists 101 publications tagged with the label 'experience' in the last 15 years. (http://www.inth.ugent.be/bibliography/, accessed 02/02/2015)

${ }^{5}$ Their central works are Frank Ankersmit, Sublime Historical Experience (Stanford, Stanford University Press, 2005), Eelco Runia, Moved by the Past: Discontinuity and Historical Mutation (New York, Columbia University Press 2014), Hans-Ulrich Gumbrecht, Production of Presence: What Meaning Cannot Convey (Stanford, Stanford University Press, 2004).
} 
that 'presence' and 'historical experience' could make us forget narrativism's insights about the nature of historical representation and historical writing that have been so important for the field of theory of history since the 1980's. The central insight of narrativism was that historical representation is always underdetermined by the historical facts, and hence, historical writing is always as least as much the result of linguistic conventions and the imagination of the historian than of the historical facts or the past itself. This allowed theorists of history to develop an ideological critique of history-writing: historical representations that were presented as the past or the historical facts themselves could now be unmasked as programmatic writings, motivated and determined by linguistic conventions and underlying ideological assumptions. Hence, the claims, made by proponents of presence and historical experience, of the possibility of a direct contact with the past, actually seem to be a full-out attack on narrativism. It is therefore not surprising that the rise of 'presence' and 'historical experience' has been met with scepticism, and in some cases even with outright hostility, by theorists loyal to narrativism and the linguistic turn. In a recent volume on 'presence', for example, Vincent Pecora expresses serious doubts about presence's claim of being able to escape the prison house of language, and Susan Crane is sceptical about the idea the past might, in some way or other, 'speak for itself'. ${ }^{6}$ In a book-length discussion on the work of Frank Ankersmit, Peter Icke states that the notion of historical experience re-introduces the idea of a direct an unproblematic access to the past itself, in this way sidestepping the accomplishments of narrativism in criticizing the realist assumptions of history writing. ${ }^{7}$ Paul Roth more or less agrees with Icke, and fears for the fact that an appeal to historical experience as the foundation of historical enquiry might ignore the subtleties of philosophy of language that philosophers have developed since the linguistic turn. ${ }^{8}$ Keith Jenkins, on the other hand, is afraid that the attention for historical experience might result in a gloomy and pessimistic form of navel-gazing with little or no attention to the ideological context of history-writing, or to the critical function of theory of history. ${ }^{9}$ And although they express it in a much less vehement way, Ethan Kleinberg, Rik Peters and Berber Bevernage express a similar concern with respect to the concept of presence: the emphasis on 'letting things be' or 'letting things speak for themselves' might endanger the critical and emancipatory potential of theory of history, they say. ${ }^{10}$

In this paper I will leave aside the question whether these criticisms, concerns and attacks are justified or not, and focus on a more shadowy side of the experience versus language debate. More specifically, I want to highlight and investigate an unspoken assumption, shared by both parties, that

\footnotetext{
${ }^{6}$ Vincent Pecora, Be Here Now: Mimesis and the History of Representation, in Ranjan Ghosh \& Ethan Kleinberg (eds), Presence. Philosophy, History, and Cultural Theory for the Twenty-First Century (New York, Cornell University Press, 2013), 42-44, Susan Crane, Of Photographs, Puns, and Presence, in Ranjan Ghosh \& Ethan Kleinberg (eds), Presence. Philosophy, History, and Cultural Theory for the Twenty-First Century (New York, Cornell University Press, 2013), 78.

${ }^{7}$ Peter Icke, Frank Ankersmit's Lost Historical Cause. A Journey from Language to Experience (New York, Routledge, 2011), 153.

${ }^{8}$ Paul Roth, Whistling History: Ankersmit's neo-Tractarian theory of Historical Representation, Rethinking History 17/4 (2013), 559-560.

${ }^{9}$ Keith Jenkins, Cohen contra Ankersmit, Rethinking History 12/4 (2008), 548.

${ }^{10}$ Ethan Kleinberg, Presence in Absentia, in Ranjan Ghosh \& Ethan Kleinberg (eds), Presence. Philosophy, History, and Cultural Theory for the Twenty-First Century (New York, Cornell University Press, 2013)24, Berber Bevernage, Time, Presence and Historical Injustice, History and Theory 47/2 (2008), 151, Rik Peters, Actes de Présence: Presence in Fascist Political Culture, History and Theory 45/3 (2006), 362-374.
} 
goes unnoticed all too often: the idea that there is a necessary trade-off between language and experience.

The large majority of critics of experience and presence almost automatically assume that there is a trade-off between narrativism, language, meaning or representation on the one hand, and experience or 'presence' on the other. The more historical representation there is, the less historical experience has a chance of manifesting itself, and vice versa. Hence, the rise of historical experience and presence is thought to entail a danger for narrativism and its accomplishments. This is in part an explanation for the fierceness of some of the criticism direct to historical experience and its proponents. Surprisingly, this is the one point on which the new theorists of presence and historical experience actually seem to agree with their critics. The concepts of presence and historical experience are often defined in direct opposition to the notions of narrativism or historical representation.

Hans-Ulrich Gumbrecht, for example, envisages a rather sharp distinction between cultures oriented towards meaning and those tending towards presence. ${ }^{11}$ The first kind is based on an 'eccentric' view on human subjectivity: the subject stands outside of the world, looks at it from a bird-eye's view, and endows the objects and events it observes with meaning. The second type sees human existence as fundamentally in the world, and between the events, objects and beings of that world. The world is not a phenomenon to be observed, but rather an event to take part in. Hence, Gumbrecht's distinction between cultures oriented towards 'meaning' and those based on 'presence' relies on a spatial metaphor: the distinction between inside and outside. And as a result, 'presence' and 'meaning' are mutually exclusive: one simply cannot be close by and far off at the exact same time. Gumbrecht does of course cite a number of occasions in which language in which language or meaning on the one hand and presence on the other can be intertwined, such as the language of the mystic, or the presence of spoken words in their audible form. Nevertheless, these are cases in which language and experience (not unlike Romeo and Juliet) overcome the barrier that separates them for a brief and special moment. This does not at all mean that the barrier is not there, quite the contrary even. Situations such as the ones Gumbrecht describes are always exceptional ${ }^{12}$, and not really relevant for the everyday ways we deal with the world or, for that matter, with history.

Eelco Runia as well makes a clear-cut distinction between representation and experience, or presence. Just as Gumbrecht, he states that there are two essentially different ways in which we can relate to the past. The first is based representation and meaning: it is the linguistic operations which we humans use to come to terms with the surrounding world in general, and with the past in particular. In this way, we are active, and the past is passive: we endow the past with meaning in order to be able to live with it and create a collective self-identity. ${ }^{13}$ The second, however, is a way in which we are passive, and the past takes in an active form. In some cases, the past can influence us on an unconscious level, and manifest itself in the way it steers our actions. Runia's most famous example is the report written by the Dutch historians of the NIOD commission on the role of the Dutch UN battalion in the Srebrenica massacre: because the historians unconsciously identified with the Dutch soldiers, they actually reproduced part of the conditions that had led to the massacre. According to Runia, the final report conveyed an atmosphere of 'forget about it', and refused to think

\footnotetext{
${ }^{11}$ Hans-Ulrich Gumbrecht, Presence Achieved in Language, History and Theory 45/3 (2006), 319.

12 Ibid. 325.

${ }^{13}$ See Eelco Runia, Burying the Dead, Creating the Past, History and Theory 46/3 (2007), 313-325.
} 
about the question of responsibility. In this way the past, the way of thinking that was present in Srebrenica, found its way into the present through the unconscious part of the minds of the historians of the NIOD. Another, somewhat more prosaic example, is the roll call ceremony that was held in order to commemorate Holocaust victims ${ }^{14}$. By simply reciting the names of the victims (rather than fitting them into a more complex form of representation), we allow something of their 'presence' to manifest itself to us, so Runia says.

The latter example already points to the fact that Runia believes there is a trade-off between language and presence. Presence needs language, but only as a vehicle, and the 'thinner' the linguistic and representative crust is that language places over the past, the better 'presence' has a chance of breaking through. For example, Runia states that modern commemorative monuments such as the Berlin Holocaust Memorial have a much stronger 'presence' in our world than nineteenth-century statues, precisely because are less 'representative': it is much less clear what they mean, and hence, they have a more unsettling presence in our world, as Fremdkörper that invade our everyday reality. ${ }^{15}$ Hence, just as Gumbrecht, Runia sketches a strict division between language and representation on the one hand, and presence on the other. Language and representation are conscious, while presence is unconscious. When language and representation are abundant, presence is absent and vice versa. ${ }^{16}$

Even Frank Ankersmit, the godfather of the modern notion of historical experience, does not escape the sharp opposition between language and experience. Although his earlier notion of historical experience is quite diverse ${ }^{17}$, he started to define it in a more focused way as 'sublime historical experience' during the course of the 2000's. Ankersmit's notion of 'sublime historical experience' is very close to a form of collective historical trauma. It is a nostalgic longing for a past that is forever gone, as a consequence of a great rupture in which society gets split into a past and a present that are essentially different. Ankersmit's typical example here is the French Revolution, which created the division between the modern world and the ancien régime. Ankersmit's thesis now is that the writing of history arises as a consequence of this. Writing history is essentially a symptom of the problematic relation of a society with its past: the people of a society unconsciously long for the past, but at the same time realize that the past can never return. The compromise, then, is starting to write history, and represent the past through the means of historical representation.

Just as Gumbrecht and Runia, Ankersmit's notion of sublime historical experience implies a stark contrast between language and experience. Sublime historical experience is the starting point of any inquiry into history, while historical writing or representation is its result. So, although the two factors of the equation need each other (without historical experience, there would be no historical writing, and without historical writing, we would never know of the existence of historical experience), there is very little mutual influence: (sublime) historical experience is one thing, and historical representation is quite another.

To summarize, according to the three most important supporters of historical experience and presence, experience and narrative are maybe not exclusive in an ontological sense (in the sense that

\footnotetext{
${ }^{14}$ Eelco Runia, Namen Noemen, Tijdschrift voor Geschiedenis 119, 2006, 242-248.

${ }^{15}$ Eelco Runia, Presence, History and Theory 45/1 (2006), 17.

${ }^{16}$ Eelco Runia, Waterloo, Verdun, Auschwitz. De Liquidatie van het Verleden (Amsterdam, Meulenhoff, 1999), 21.

${ }^{17}$ Frank Ankersmit, De Historische Ervaring (Groningen, Historische Uitgeverij, 1993)
} 
both cannot exist simultaneously), but they are exclusive in terms of scope: if we study experience, or experience-related notions such as 'presence', we need not bother with the role of language, narrative or representation, and vice versa. In Gumbrecht's spatial metaphor, presence is close-by, while language (or meaning) is far away. For Runia, representation is conscious and intellectual, while 'presence' is unconscious and emotional. For Ankersmit, finally, experience is the starting point of historical enquiry, and representation is its end point. In all three cases then, language and experience are mutually exclusive: one cannot be close by and far off at the same time, something cannot be conscious at the same time, and the same thing cannot be simultaneously at the beginning and at the end of historical enquiry.

In this sense, the critics of historical experience seem to be right, maybe not necessarily in their arguments, but at least in their concern: if narrative and experience are indeed mutually exclusive, then it is true that the rise of historical experience as a topic in theory of history is a threat for narrativism and its legacy. Even if (in the best case) the claims of historical experience do not directly contradict those of narrativism, then there is at a least a practical opposition: any attention devoted to historical experience is automatically attention that is not devoted to narrativism. As a result, even if the conclusions of narrativism and the linguistic turn might not openly be denied, they still run the risk of being neglected or forgotten.

\section{Language and Experience?}

But is this really necessarily true? Is there something intrinsic about experience and language that keeps them apart? Or is they a way to escape this seemingly unavoidable but still relatively unexamined, assumption? If there is, this could be important for the future of both narrativism and historical experience. If there is a way in which historical experience can be understood without standing into opposition to narrativism, language and representation, then the quarrel between narrativism and experience can come to a close, and theory of history can move on to the much more interesting, debate about how the insights of narrativism can be used and applied in other domains.

Needless to say I believe there is such a way. More specifically, I believe it is possible to reimagine a concept of historical experience so that it does not require the binary opposition between experience and language used by Gumbrecht, Runia or Ankersmit. If such an account were possible, then this would entail that we have a concept of historical experience on our hands that this does not require an opposition to language or representation, and hence can carry the insights from the narrativist tradition beyond this tradition itself, and into a new area of research in historical theory.

The best way to start thinking about this is by taking a look at two lesser-known theorists of historical experience, who have explicitly written about historical experience in a linguistic context, about a form of historical experience that is actually created by representational, 'narrativistic' means. The first is Andrew Abbott who, in 2008, wrote a paper ironically called 'Against Narrative: A Preface to Lyrical Sociology'. ${ }^{18}$ Abbott, however, does not argue against the use of language or representation as such, but against a rather specific interpretation of 'narrative'. Abbott defines 'narrative' as a way of writing that describes its subject as a gradually unfolding history, a story with a beginning, a middle and an end. ${ }^{19}$ Writing narratives such as these is a contextualizing enterprise, and happens

\footnotetext{
${ }^{18}$ Andrew Abbott, Against Narrative. A Preface to Lyrical Sociology, Sociological Theory 25/1 (2008).

${ }^{19}$ Ibid. 69
} 
from a third person, bird's eye point of view. The counterpart of narrative is not 'experience' or 'presence', but 'lyrical' writing. When discussing Wesley Harvey Zorbaugh's The Gold Coast and the Slum as an example of 'Iyrical sociology', Abbott describes it in the following way.

For telling a story is precisely what Zorbaugh does not do. He rather looks at a social situation, feels its overpowering excitement and its deeply affecting human complexity, and then writes a book trying to awaken those feelings in the minds - and even more the hearts - of his readers. This recreation of an experience of social discovery is what I shall here call lyrical sociology. ${ }^{20}$

Hence, lyrical writing, the counterpart of narrative, is not itself a form of experience, but rather the re-creation of experience through linguistic means. And the experience it re-creates is not a kind of direct access to the past, nor a direct presence of historical reality. Rather, it is a specific state of mind of a specific individual, simply the way somebody feels when looking at social reality.

My second example is the historian Adrian Jones. Jones pleads for a so-called vivid history, a history which evokes images of the past rather than posit claims or prove theses about it. ${ }^{21} \mathrm{He}$ sees a parallel between the current way in which history is written and the situation in the beginning of the twentieth century against which the Annales-school was a reaction. ${ }^{22}$ The dominant way of writing history in the beginning of the twentieth century was fragmented, obsessed with detail and concerned with the analysis of texts rather than with an evocation of the past itself in its totality. There is a remarkable similarity between this situation and our current one since the linguistic turn, Jones states. History as such no longer exists; there is only class history, gender history, ${ }^{23}$ In the same way, focus has shifted from what the past itself was like to how people have represented the past. ${ }^{24}$ (Jones 2000, 537). Jones then pleads for a reaction which is analogous to that of the founders of the Annales: a return to a way of writing history which has a sense of the past as a whole, as the evocation of a foreign world. He calls this way 'vivid history', and refers (among others) to Tacitus to illustrate what this means. The important thing about Tacitus and his writings was that he did not take in a contemplative, distanced and contextualizing point of view. Tacitus was a traditional roman patrician full of noble ideals who saw himself confronted with a messy past full which seemed to contradict his ideas. ${ }^{25}$ Hence, the way he writes about this past expresses the outrage he feels when looking at it. Tacitus cannot contextualize the events from the past into some general narrative or explanatory scheme, since the scheme he has in mind (based on the nobility of Roman culture and patricianhood) fails to capture the historical events. Hence, he does not try to understand or contextualize the course of the past. Rather he describes the events not as part of a general process, but as events sui generis, and he expresses the moral outrage he feels when he looks at them.

For us, the interesting thing is that Abbott and Jones, just as Gumbrecht, Runia and Ankersmit, try to formulate an alternative to the narrativistic way of looking at our relation with the past. They want a relation with the past which is less constructed, and more authentic, intuitive and experiential. But

\footnotetext{
${ }^{20}$ Ibid. 70.

${ }^{21}$ Adrian Jones, Vivid History: Existentialist Phenomenology as a New Way to Understand an Old Way of Writing History, Storia Della Storiografia 54 (2008), 42.

${ }^{22}$ Adrian Jones, Word and Deed: Why a Post-post-structural History is Needed and how it Might Look, The Historical Journal, 43, 539.

${ }^{23}$ Ibid. 528.

24 Ibid. 537.

${ }^{25}$ Adrian Jones, Vivid History: Existentialist Phenomenology as a New Way to Understand an Old Way of Writing History, Storia Della Storiografia 54 (2008), 43-47.
} 
unlike Gumbrecht, Runia and Ankersmit, they try to find this alternative within language rather than outside of it. Abbott and Jones do not talk about an unconscious (Runia) or unmediated (Gumbrecht) presence of the past, nor about a kind of traumatic collective nostalgia (Ankersmit). Rather, they try to formulate a different way of writing about the past: not something outside of language, but rather a different way of employing language, or historical writing, as a way to communicate and convey experience.

The question then is: what does this entail exactly for the concept of historical experience? Abbott and Jones do talk about a way of writing that appeals more to the heart than to the mind. Hence, one could say that it would tend more towards experience and feeling, and less towards cognition and understanding. But can we genuinely name this form of experience "historical experience"? What exactly is it that is 'historical' about 'historical experience' in this sense? Do we mean to say that we 'experience' the past? How can this be possible at all? And why would one way of writing be able to arouse or convey this and experience, and another one not?

Let us start by supposing, for the sake of the argument, that there is indeed a way in which language, (or narratives) can arouse or convey some kind of experience of the past. Starting from the hypothesis will allow us to determine what its necessary preconditions are, and this in turn will enable us whether the idea of a language-friendly form of experience or presence makes sense. The first thing this hypothesis implies is that there should also be a way in which language does not convey experience. After all, if we would say that all forms of language create historical experience all of the time, we would have to redefine the concept of historical experience to such an extent that most of its substantive content would disappear. We would also lose the possibility of making a difference between different kinds of historical writing, and hence make any kind of critical or appreciative perspective on the writing of history impossible from the outset. This is, I believe, not what we want. Hence, the first precondition is in place: we need an account which distinguishes between two different functions of language, and we need an argument why one can arouse experience while the other cannot.

A second precondition has to do with the representative abilities of language and narrative: if we want our experience to be a historical experience, an experience which is more than an experience of ink and paper (or pixels) and our own mental states, we need some way of arguing that language can transport something 'authentic' or 'original', an original meaning, or an authentic experience, from the past to the present. Hence, we are in need of philosophy of language that has a certain amount of trust in the ability of language to transport something essential or meaningful from the past to the present. Traditional theories of language, however, will not do. One could, for example, try to start from a classical correspondence theory of truth, and state that a certain piece of writing can create a historical experience in the minds of its readers when it adequately mimics the events or situations in the past it writes about. This is more or less what R.G. Collingwood stated in his 'Principles of History' and 'The Idea of History'. This correspondence theory, however, has been severely discredited by both analytic (Quine and the later Wittgenstein) and continental (Derrida, Foucault and many others) philosophers of language, as well as by the narrativist tradition itself. It may be that some aspects of it can be salvaged, but even the strongest supporters of Collingwood will no longer support the strong interpretation of his theory sketched above. The narrativistic view of language itself, however, will not be of much help either. Narrativism is built on the core assumption that the written language of historical representation is first and foremost a human creation, and that its most important 
features are creative accomplishments of the author, and that there is no real meaning to be found in the past itself.

Hence, if we truly want a theory of historical experience that allows for the creation of a genuine 'historical' experience though written texts, we are in need of something different. We need a philosophy of language in which language is not seen as a representation or a distortion of reality, but rather as a way of conveying experience. We also need some kind of argument to be able to state that the experience conveyed in this way is indeed a genuine 'historical' experience, and not solely an experience of something in the present (such as the reader's own state of mind, or the words on a piece of paper), that just accidently happens to be the consequence of reading a text about the past. Furthermore, if we as theorists of history want to make any difference at all for the actual writing of history, we also need a philosophy of language than can show us why conveying experience through language can be a good thing, and how we can distinguish it from a use of language which does not do it.

There are different ways in conceiving such a philosophy of language. Adrian Jones himself has set some steps in this direction, by creating a conceptual division between language that aims to prove a thesis (of which the gospel of St John is the original example), and language that tries to convey or create a state of mind (embodied in the writings of Herakleitos). ${ }^{26}$ In his contribution to this volume, Zoltan B. Simon develops a phenomenological approach to the matter, and re-imagines historical writing as an expressive phenomenon that springs from an aesthetic form of historical experience. ${ }^{27}$ I do not hold anything against these promising proposals, and it might well be that there are even more possibilities to solve the matter that are as yet unexplored. In this paper, however, I would like to suggest a different route: I believe we can find a ready-made version of the philosophy of language we need in the existentialist philosophy of language of the Jewish philosophers Martin Buber and Emmanuel Levinas.

\section{Buber and Levinas on Dialogical Ethics}

Although there are some subtle and not unimportant differences between the philosophies of Buber and Levinas ${ }^{28}$, we can safely leave those aside for the purpose of this paper, and instead focus on what they have in common. Levinas and Buber both follow the spirit of existentialist philosophers such as Kierkegaard, Nietzsche and Heidegger, and construct a philosophy that favours existence over essence. Whereas more traditional philosophers will start from a ontological picture of the world and use that to derive their views about concrete human life, existentialists always start from life itself, and use this as a foundation to build their philosophy. Hence, theoretical constructs such as science, politics or jurisdiction are not seen as standalone abstract constructions, but as parts of human life itself. The distinctive feature of Buber and Levinas then, is that they see human life as essentially relational. Contrary to other existentialist philosophers such as Heidegger, Kierkegaard or Sartre, they do not put an emphasis on the life-world of the individual. Rather, they see being essentially as being with others, as a process of meeting and relating to other human beings. This

\footnotetext{
${ }^{26}$ Adrian Jones, Reporting in Prose: Reconsidering Ways of Writing History, The European Legacy, 12 (2007), 311-336.

${ }^{27}$ See also Zoltan Simon, Experience as the Invisible Drive of Historical Writing, Journal of the Philosophy of History 7/2 (2013), 183-204.

${ }^{28}$ For this, see Peter Atterton, Levinas \& Buber: Dialogue and Difference (Pittsburgh, Duquesne University Press, 2004).
} 
means that life is, always and in essence, ethical. Or, in Levinas' words: not metaphysics, but ethics is the 'first philosophy': the essence of the human condition and the necessary starting point of all philosophy. ${ }^{29}$

It is important to note that both Buber and Levinas' use of the term 'ethics' diverges significantly from its traditional use in ethics and moral theory. For the two Jewish philosophers, ethics has anything with following the right rules, creating happiness and well-being, or moulding one's personality in the right way. Rather, ethics is essentially about the recognition of the other as a worthwhile human being, as a specific individual who is talking to me here and now, and who cannot be reduced to an instance of some general category. This means that the relation with the other is, both for Buber and Levinas, more a matter of experience than of behaviour or knowledge. It is not about performing the right actions or knowing the right rules. Rather, the encounter with the other is an experience of a singular event, an event that cannot be caught be a controllable procedure that can be used to predict or analyse it. What is interesting for us here is that both philosophers also have a more specific, existential view on language. Rather than looking at language as a way to represent reality to an observer, or as a means to communicate information, they see it at as way of living, of being in the world, and, first and foremost, of being with others. Furthermore, both Levinas and Buber also make a distinction between two different functions of language: one which creates and affirms the ethical (and therefore experiential) relation with the other, and one that denies or ignores it.

For Martin Buber, the essence of the human condition is twofold, and is represented by one's possibility to speak to two different word pairs: 'I-You' and 'I-It'. ${ }^{30}$ The I that is able to say 'you' to the other and to the world in general is the I of engagement, sympathy, respect and responsibility, the I of an interpersonal, experiential and living world. The ' $I$ ' that says ' $I t$ ', on the other hand, is the I of a world of impersonal things, of distance, objectivity and of general categories. One could be tempted to see the first pair as denoting our relation with people and the second that with material objects. Buber, however, is very clear about this: the two word pairs are functions of language and ways we relate to the world, and are not bound by the nature of the things they refer to. It is perfectly possible to say 'you' to nature (Buber gives the example of a tree and a cat) ${ }^{31}$ or to material reality (which is what happens in $\mathrm{art}^{32}$ ). On the other hand, it is also very well possible to say 'it' to our fellow human beings, for example when we use them only as a means to something else, or when we reduce them to nothing more than instances of a general kind, such as 'customer', 'patient', 'consumer' or 'voter'. The structural nature of the two central Buberian functions is language is particularly important for us, since it means that both ways of using language can, at least in principle, also be used with respect to our relation with the past.

Emmanuel Levinas holds a view that is remarkably similar. Just as Buber, he distinguishes between two very different functions of language, namely 'Le Dire' or 'The Saying' and 'Le Dit' or 'The Said'. ${ }^{33}$ The Saying is language as it is used by concrete people in real, specific situations. It is fundamentally

\footnotetext{
${ }^{29}$ Emmanuel Levinas, Ethique Comme Philosophie Première, Paris, Rivages, 1998.

${ }^{30}$ Martin Buber, Ich und Du (Heidelberg, Lambert Schneider, 1983), 10.

${ }^{31}$ lbid. 7 \& 93.

${ }^{32}$ See Martin Buber, Der Mensch und Sein Gebild (Heidelberg, Lambert Schneider, 1955).

${ }^{33}$ Emmanuel Levinas, Autrement qu'Etre ou au-delà de l'Essence (Den Haag, Martinus Nijhoff, 1978) 1.3. (For matters of convenience (easily finding one's way in different editions and translations), I will use chapters rather than pages to refer to Levinas' writings.
} 
open and creative: the meaning of words and expressions changes constantly, and are re-invented in every specific situation. Seen in this way, the openness and dynamic nature of language allow us to account for the uniqueness and the unpredictability of the other and the concrete moral situation. In Levinas' own religiously inspired words: language has the ability to create 'revelation'. ${ }^{44}$ 'Le Dit' ('The Said'), on the other hand, refers to language as a solid and abstract system. Here, the use of language is subject to general rules, structures and hierarchy, and the contingent is always subsumed under some general, abstract term. Used in this way, language can suppress the otherness and uniqueness of the other that was created with the help of the Saying.

\section{Buber and Levinas on History}

There are several reasons why Buber and Levinas' views can be very interesting for the discussion between narrativism and historical experience in theory of history. I have argued above that, in order to overcome the opposition between language and experience, we need a view in which language has the potential to create or convey experience. This is exactly what Buber and Levinas have to offer. Hence, it is not a coincidence that much of their description of the 'You' and the 'Saying' reminds us of the way theories of historical experience are presented. As said, the theorists of historical experience wanted a relation with the past which is more personal, direct, authentic and intuitive, and less intellectualized and scholarly. Traditionally, it has often been assumed that this implies a move away from language, and hence also from narrativism. But when we look again at this point through a Levinasian or a Buberian lens, things are very different. It just seems as if the theorists of historical experience just want to move from the 'I-it' to the 'I-You', or from 'The Said' to 'The Saying'. And actually, this does not imply a move away from language at all, but merely a move from one functionality of language to another. It is also a view which is compatible with the central insight of narrativism, namely the underdetermination of historical writing by the historical facts. As said, narrativists emphasize the fact that historical representation is always for a large part the result of linguistic conventions, as well as of the personality and imagination of the historian. Hence their suspicion of the concept of experience, which is often seen as implying a direct, definitive and unquestionable contact with the past. For Buber and Levinas, however, experience is no such thing. The experience of the encounter with the other is not an objective or universally valid experience. On the contrary, it is, by its very nature, always personal and contingent, and cannot simply be transferred from one situation to another. It is always deeply personal, and hence can only exist by the grace of the creativity and dynamic nature of language: by the fact that words, sentences and expressions do not have fixed meanings, but are created anew in every encounter with the other. Hence, this is exactly the dynamic and personal view on language and its use that narrativists employ.

Reformulating the dilemma in this ways means that we have an answer to the questions surrounding Jones and Abbott's accounts of the experiential dimension of historical writing. As said, both Abbott and Jones advocated a seemingly more experiential way of writing history, but it was unclear what this meant exactly: what was this 'experience' an experience of? With Buber and Levinas' views, we now have a putative answer: it is an experience of a genuine encounter with another human being, made possible by linguistic means. And in the case of writing history, these linguistic means are exactly those that Abbott and Jones describe: the personal and engaged vivid or lyrical use of language by the historian. So, it may not be a direct experience of the other from the past in the very

\footnotetext{
${ }^{34}$ Emmanuel Levinas, Totalité et Infini. Essai sur l'Exteriorité(Den Haag, Martinus Nijhoff, 1971), 1.B.5.
} 
strict sense. But it is still an experience of a genuine encounter with the other from the past, and hence something more than merely an experience of one's own state of mind when reading a narrative. Hence, there is indeed a sense in which we can refer to this kind of an experience as a 'historical' experience, since it really needs a contact or relation with the past and the people that live there as its central precondition.

Some people might object, however, and say that this phenomenon might be 'historical' in some sense, but that it still isn't a 'real' experience. Monika Fludernik for example prefers to talk about 'experientiality', experience that has passed through an analytical or didactic reworking, rather than about 'experience' ${ }^{35}$ I have no problems with this, though I do suspect that the distinction between experience and experientiality might be easily deconstructed. Do not all forms of experience, even the seemingly direct and unmediated ones, require some level of conceptual 'filtering' or didactic reworking? In any case, this is not something I am concerned with in this paper, since in my view it does not really matter whether one names the phenomenon I am talking about 'experience' or 'experientiality'.

Of course, the parallel between historical experience (or experientiality) and the Buberian or Levinasian experience of the encounter with the other is not as straightforward as that. First of all, Buber and Levinas' theories are first and foremost about an interaction between two people: myself and the other. In the writing of history, however, three parties are involved: the historian, the reader and the people from the past the historian writes about. The relation between the reader and the people from the past is mediated by the historian. Furthermore, Buber and Levinas were clearly thinking mostly about interactions between people in the present, and not about a relation between people in the present (the historian and the reader) with people from the past. So, even though Buber and Levinas might offer us a solution for the dilemma between language and experience, it is still not clear exactly what this would mean on a less abstract level. What would a Buberian or a Levinasian view, or more generally, a view from existentialist ethics, look like when applied to the writing of history?

Part of the answer can be found in the writings of Buber and Levinas themselves. As I said, both philosophers developed their theories thinking primarily about interactions between people in the present. Nevertheless, they also made several small but important remarks in which they indicate that their analysis extends to our relation with people with the past as well. Buber mentions this when he talks about the concept of the 'We'. In short, the 'We' is the community of people who are in a genuine 'I-You' relation with each other. The 'We' can include people from our vicinity, but also people who are far away. One should not understand as a concrete social entity, such as a family, a village or a nation. Rather, the ' $W e^{\prime}$ ' is a kind of spiritual feeling of community, made possible by the ability of language, the spoken and written word, to transcend the boundaries of physical proximity. Hence, Buber also states that this ' $W e^{\prime}$ can also include the people from the past ${ }^{36}$, the people historians write about. For Buber, the fact that our encounter with the people from the past is mediated by the language of the historian doesn't really matter: every encounter with the other is

\footnotetext{
${ }^{35}$ Monika Fludernik, Experience, Experientiality and Historical Narrative. A View from Narratology, in Thiemo Breyer \& Daniel Creutz, Erfahrung und Geschichte: Historische Sinnbildung im Pränarrativen (Berlin, De Gruyter, 2010), 49-50.

${ }^{36}$ Martin. Buber, Dem Gemeinschaftlichen Folgen, in Martin. Buber, Logos: Zwei Reden (Heidelberg: Lambert Schneider, 1962), 67.
} 
mediated by language anyway, and the fact whether the other is physically present or not does make a difference, but not an essential one.

Levinas actually has a more sophistacted account to back this up: unlike Buber, he does make a more explicit distinction between an immediate, physical encounter with the other on the one hand, and one in which the other is not directly present, but represented by some kind of linguistic or conceptual system on the other. Levinas denotes the other in the latter situation as 'The Third', ${ }^{37}$, the absent other or, in the words of Howard Caygill, the 'spectral' other. ${ }^{38}$ Levinas' typical examples of the Third are the other as represented in jurisdiction or politics. In the case of politics, the number of people in a community is simply too large to organize direct face-to-face meetings with everyone. Hence, we need to think of a structured system of political representation and the appropriate discourse that goes with it, such as representative democracy for example. In the case of jurisdiction, the problem of the large number of people is combined with the principle of justice: in order to make sure that people at different places and different times are treated equally and fairly, we need an ordered system of juridical concepts and, again, an appropriate form of discourse in order to employ them. Hence, it is only a small step to the representation of the other from the past: because the other from the past cannot be present in the present, we need a linguistic structure to represent her, and create the same kind of substitute encounter with the other that is constantly used and recreated in politics and jurisdiction.

This linguistic structure is exactly what the writing of history is, or at least what it can be. Levinas also seems to support this idea, by mentioning that the other from the past indeed has the status of the Third. ${ }^{39}$ True, Levinas is also very critical of the objectivist pretentions of some forms of historywriting that do not approach the people they write about in an engaged way, as complex and worthwhile human beings ${ }^{40}$. But this is actually exactly what we need. As said, in order to transcend the opposition between language and experience, we need a philosophy of language that can distinguish between two functionalities of language: one which creates a distanced, third-person perspective (the one against which theorists of historical experience react) and another one which is in line with what they propose: an engaged, personal, emotional and experiential relation with the past. Hence, Levinas' criticism of history-writing actually runs quite parallel to the objections of the theorists of historical experience to the narrativist tradition. Hence, it is no surprise that Levinas' own point of view is in line with theirs as well.

What, then, would be the result of all of this? If we follow Levinas and Buber's leads, we can imagine a view in which the language of the historian can create a genuine encounter with the other from the past, an encounter that is not essentially different from the personal encounters we have with the people in the present. Of course, the writing of history is a mediating undertaking, but this does not mean that a genuine encounter with the other is impossible. By using an engaged and personal writing style, a style in which the historian shows her personal engagement with, and care for, the people she writes about, and in which other is represented as a complex and unique human being,

\footnotetext{
${ }^{37}$ Emmanuel Levinas, Autrement qu'Etre ou au-delà de l'Essence (Den Haag, Martinus Nijhoff, 1978), 1.8., see also for example Robert Bernasconi, The Third Party. Levinas on the Intersection of the Ethical and the Political, Journal of the British Society for Phenomenology 30 (1999), pp 76-87

Society for Phenomenology 30 (1999), pp 76-87.

${ }^{38}$ Howard Caygill, Levinas and the Political (London, Routledge, 2002), 75.

${ }^{39}$ Emmanuel Levinas, Humanisme de l'Autre Homme (Montpellier, Fata Morgana, 1972), 1.9.

${ }^{40}$ Emmanuel Levinas, Totalité et Infini. Essai sur l'Extériorité (Den Haag, Martinus Nijhoff, 1971),3.C.2.
} 
the historian can create at least some aspects of a genuine encounter with the other. When understood in this sense, language is not a means of 'accessing' or 'disclosing' the past itself, but rather a way of 'being together', so to speak, of the people in the present and the people in the past. Jones and Abbott's descriptions of 'vivid' and 'lyrical' writing are examples of this: both theorists advocate a writing style that is hands on, personal and engaged, and the focuses on the telling details of human life, rather than taking in a bird's eye, third person perspective. With Buber and Levinas in the back of our head, we can now say that this is a sense then in which a narrative, a historical text, can indeed create a kind of 'historical experience': not an experience of the past itself, but rather the experience of a genuine encounter with a fellow human being from another time.

\section{Summary and Conclusion}

The aim of this paper was to identify a way to overcome the opposition between narrative and experience, and conceive of a way of formulating historical experience that is not adverse to language and narrative. I have argued that this way cannot be found in the most widespread versions of historical experience, namely the theories of Hans-Ulrich Gumbrecht, Eelco Runia and Frank Ankersmit. This does not mean that their theories are not viable, or wrong. They might be perfectly suited to account for those kinds of historical experience that are indeed outside the use of narratives and language (in as far as this is possible). What it does mean however, is that if we want an account of historical experience that reserves a special role for language and hence might benefit from the insights of narrativism, their theories will not do. Nevertheless, Adrian Jones and Andrew Abbott's ideas about 'vivid' and 'lyrical' ways of writing seem to suggest that this does not necessarily need to be the case, although it was still somewhat unclear what their theories could tell us about language historical experience as such. Hence, I have identified the necessary conditions for any philosophy of language that aims to be the basis of a conjunction of narrative and historical experience. Firstly, we need an account that can account for a way in which language, or narratives, can convey a form of experience that is not limited to the experience of one's own state of mind when reading a narrative. And secondly, we also need a way to distinguish between a use of language that can convey this kind of experience, and another use that cannot, or that might even inhibit it. It is very well possible that there are several consistent philosophies of language that can take up this role. In this paper, however, I have chosen to highlight one of them. I have suggested that the existential philosophies of language of Martin Buber and Emmanuel Levinas can be exactly the kind of theories we need. For Buber and Levinas, language does not stand in the way of experience. On the contrary, it is the necessary medium to create the experience of the encounter with the other. The resulting picture is one in which the historian does not try to ignore or bypass the role of language or narrative construction, but rather uses language to its fullest extent as a means to create the experience of a genuine encounter between people from the past and those in the present. 